\section{An unusual complication of eosinophilic esophagitis in an adolescent: intramural esophageal dissection}

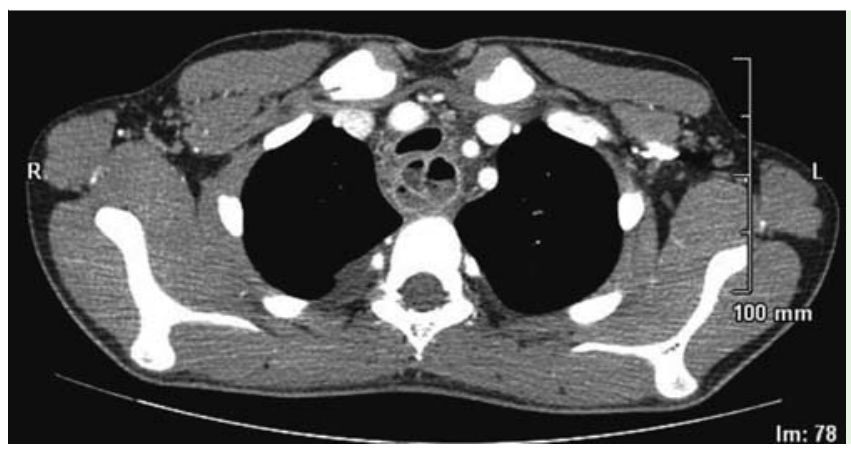

Fig. 1 Computed tomography view at onset of symptoms. Esophageal wall dissection was evident without perforation into the mediastinum.

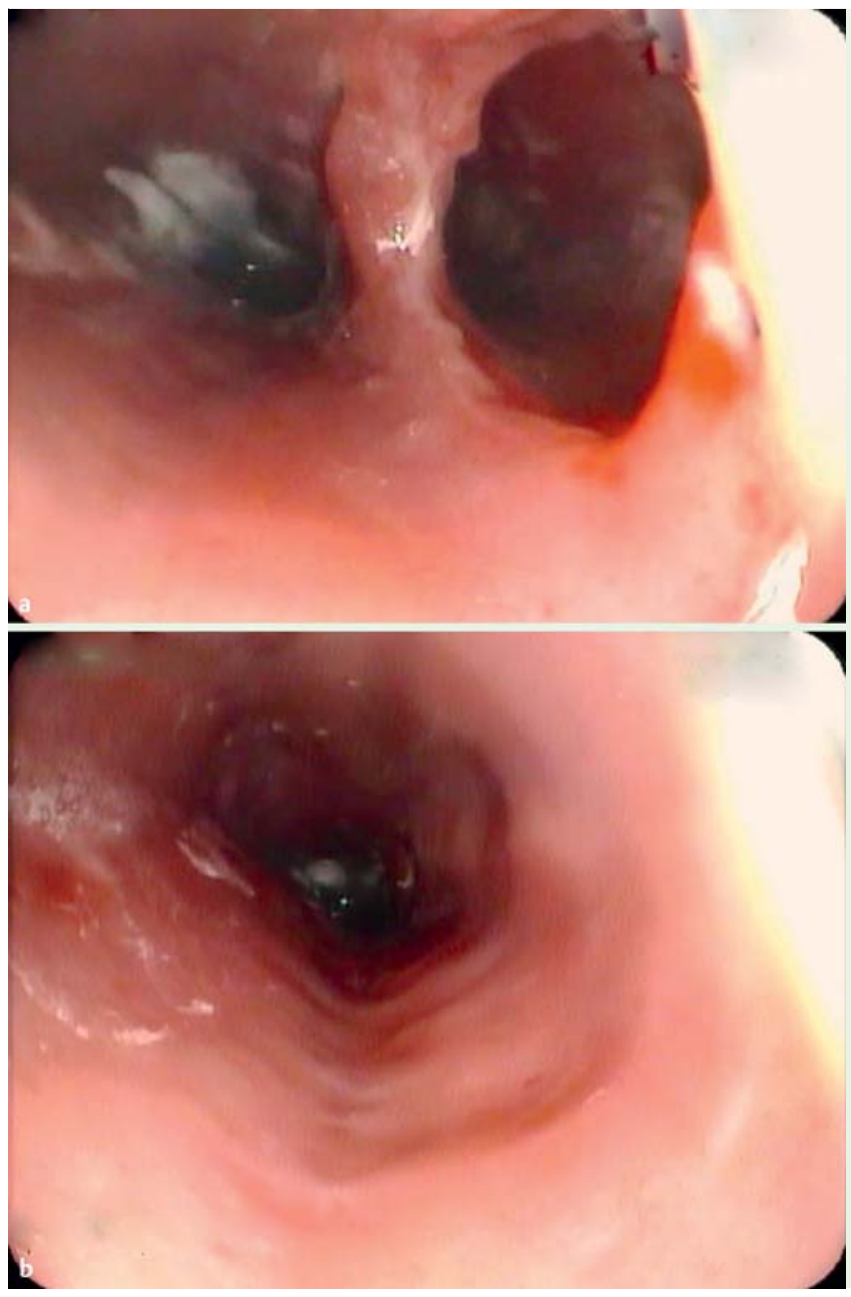

Fig. 2 Endoscopic view at onset of symptoms. a Two huge esophageal lesions filled with hematicpurulent material were detected at $25 \mathrm{~cm}$ and $33 \mathrm{~cm}$ from the dental arcade. b Diffusely inflamed fragile mucosa and corrugated esophagus with concentric rings and linear shearing were observed.
Intramural esophageal dissection is a rare complication of eosinophilic esophagitis. Only three cases in adults have been described [1-3]. The residual mucosal septum could be treated with endoscopic section $[4,5]$. We report on the first pediatric case to be treated conservatively for intramural esophageal dissection due to eosinophilic esophagitis.
A 15-year-old boy who was affected by Klinefelter syndrome presented with acute chest pain, dysphagia, and hematemesis. His past medical history was unremarkable. A computed tomography (CT) scan ( $\bullet$ Fig. 1) and urgent upper endoscopy ( $\bullet$ Fig.2) were performed. Circumferential dissection of the middle and lower part of the esophageal wall was revealed without evidence of perforation. During endoscopy, a double-lumen naso-esophageal tube was driven into the dissection and mild aspiration was started. This facilitated drainage for 21 days, during which the boy was treated by fasting and total parenteral nutrition support. The boy became asymptomatic in 4 days. After tube removal a new endoscopy was performed, which revealed a healing mucosa but also a false lumen. Esophageal biopsy samples were suspicious for eosinophilic esophagitis (defined as 15 eosinophils per high-powered field). After 20 days the presence of a 9-cm false lumen characterized by slow emptying was confirmed using contrast esophagogram ( Fig.3). The patient underwent endoscopic section of the mucosal septum under general anesthesia ( $\bullet$ Fig.4). Oral feeding was resumed 24 hours after the procedure and the patient was finally discharged after 7 days.

After a month, a control endoscopy showed good epithelialization of the esophageal wall ( Fig.5). Biopsies showed the presence of severe eosinophilic esophagitis (eosinophils $>20$ per high-powered field). Oral steroid treatment and a hypoallergenic diet were started. Follow-up endoscopy at 6 months showed a regular esophageal mucosa and normal histological findings.

In conclusion, intramural esophageal dissection in eosinophilic esophagitis should be treated conservatively if no signs of perforation are present. Endoscopic incision of mucosal septum is a safe and feasible technique to restore normal esophageal anatomy.

Endoscopy_UCTN_Code_CCL_1AB_2AC_3AH

Competing interests: None

\section{A. Sgrò ${ }^{1}$, P. Betalli ${ }^{1}$, G. Battaglia ${ }^{2}$, R. Bardini ${ }^{3}$, M. A. Crivellaro ${ }^{4}$, G. Svaluto ${ }^{5}$, P. G. Gamba ${ }^{1}$}

${ }^{1}$ Department of Pediatric Surgery, University of Padua, Padua, Italy

${ }^{2}$ Istituto Oncologico Veneto, University of Padua, Padua, Italy ${ }^{3}$ Department of General Surgery, Hospital of Padua, Padua, Italy

${ }^{4}$ Servizio di Allergologia, Medicina del lavoro, Hospital of Padua, Padua, Italy ${ }^{5}$ Department of Paediatrics, Hospital of Rovigo, Rovigo, Italy 


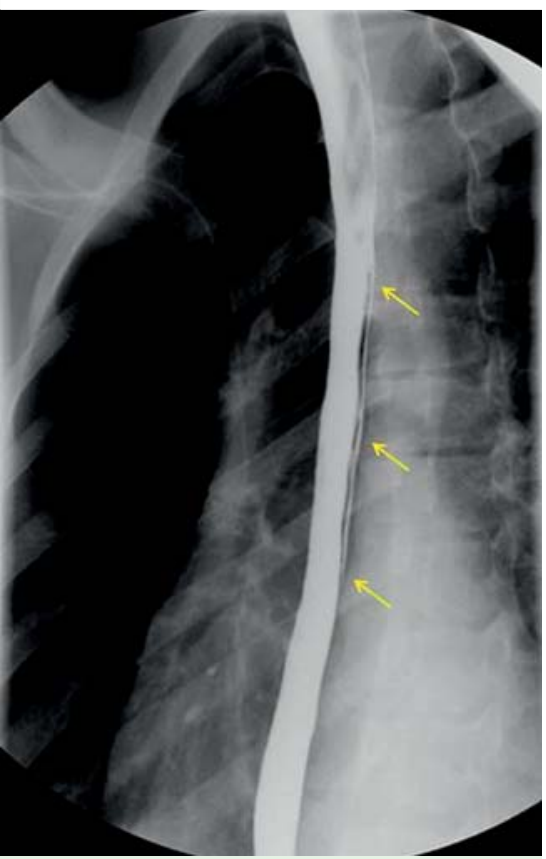

Fig. 3 Contrast esophagogram showing a persistent narrow false lumen (arrows), $2 \mathrm{~mm}$ thick and $9 \mathrm{~cm}$ long, characterized by very slow emptying.

\section{References}

1 Quiroga J, Prim JMG, Moldes M et al. Spontaneous circumferential esophageal dissection in a young man with eosinophilic esophagitis. Interact Cardiovasc Thorac Surg 2009; 9: 1040-1042

2 Liguori G, Cortale M, Cimino F et al. Circumferential mucosal dissection and esophageal perforation in a patient with eosinophilic esophagitis. World J Gastroenterol 2008; 14: $803-804$

3 Predina JD, Anolik RB, Judy B et al. Intramural esophageal dissection in a young man with eosinophilic esophagitis. Ann Thorac Cardiovasc Surg 2012; 18: $31-35$

4 Bak YT, Kwon OS, Yeon JE et al. Endoscopic treatment in a case with extensive spontaneous intramural dissection of the oesophagus. Eur J Gastroenterol Hepatol 1998; 10 : 969-972

5 Cho CM, Ha SS, Tak WY et al. Endoscopic incision of a septum in a case of spontaneous intramural dissection of the esophagus. J Clin Gastroenterol 2002; 35: 387-390

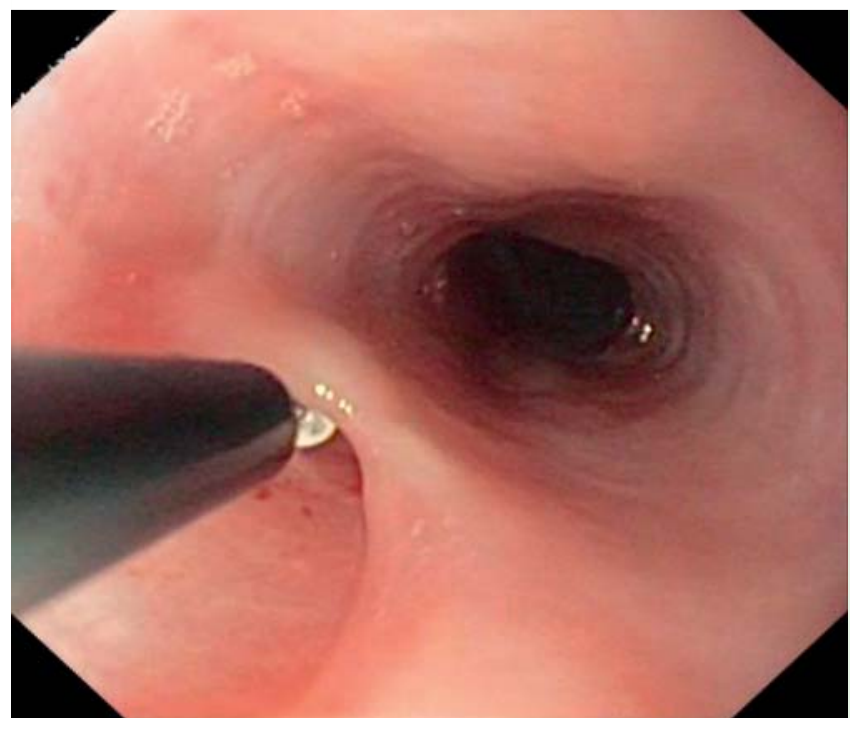

Fig. 4 A diathermic knife was used to incise the mucosal septum between the false and the true lumen, creating a unique esophageal lumen covered by normal mucosa.

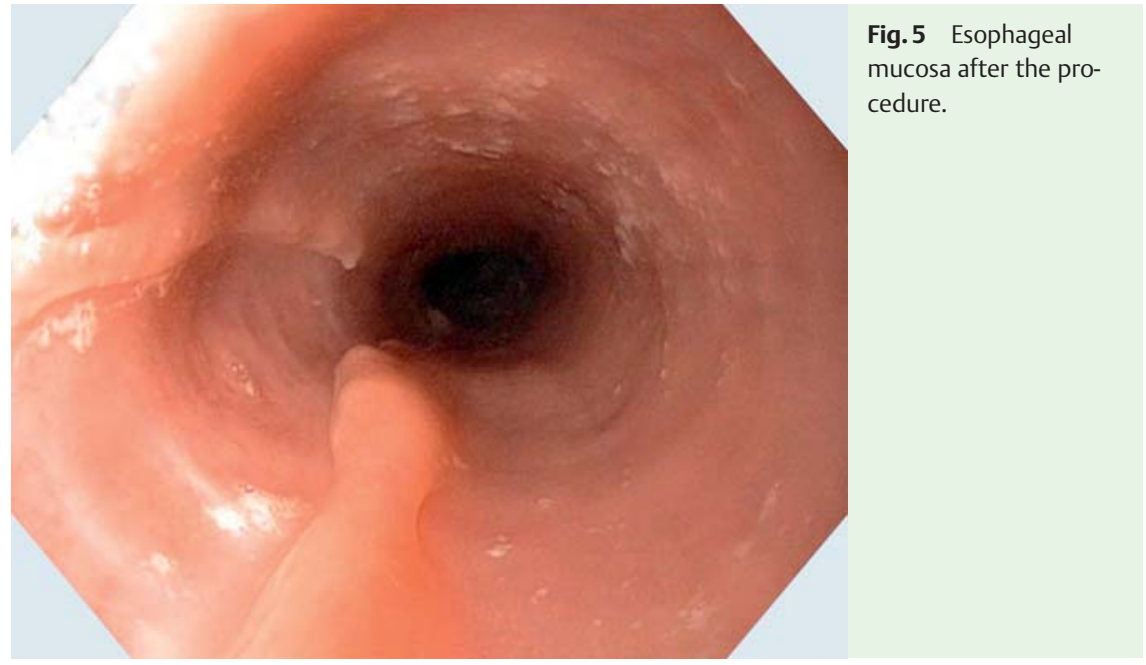

\section{Bibliography}

DOI http://dx.doi.org/

10.1055/s-0032-1325777

Endoscopy 2012; 44: E419-E420

(C) Georg Thieme Verlag KG

Stuttgart · New York

ISSN 0013-726X

\section{Corresponding author}

\section{A. Sgrò, MD}

Department of Pediatric Surgery

University of Padua

Via Giustiniani 3

35100 Padova

Italy

Fax: +39-049-8211781

albertosgro@gmail.com 